\title{
Pulmonary Carcinoma with $\beta$-Human Chorionic Gonado- tropin Expression: Further Understanding and Suggestions for This Entity from Six Cases Experience in a Single Insti- tution
}

Purpose: $\beta$-human chorionic gonadotropin ( $\beta-\mathrm{hCG}$ ) expressing pulmonary carcinoma is very rare, and little is known about this entity. The aim of this study was to find the characteristic clinicopathologic features of $\beta$-hCG expressing pulmonary carcinoma. Materials and Methods: Of all 2790 lobectomy specimens of lung excised between January 2006 and December 2010, only six cases of $\beta$-hCG expressing pulmonary carcinoma were identified retrospectively. The cases were classified according to the WHO classification, and clinicopathologic features were investigated. Results: The patients consisted of 4 males and 2 females, and the median age was 64 years. Half of the patients presented with blood tinged sputum or hemoptysis. The median tumor diameter was $4.2 \mathrm{~cm}$. All but one case showed prominent area of hemorrhage and necrosis. All six cases were pleomorphic carcinoma, composed of various types of non-small cell carcinomatous component and giant cell component. All cases showed significant area of $\beta$-hCG positivity, and $\beta$-hCG was usually expressed in the pleomorphic giant cells. Conclusion: In pulmonary carcinoma with pleomorphic giant cells, is necessary to check immunohistochemical stain for $\beta$-hCG and to follow up the serum $\beta$-hCG levels, to further establish the concept of $\beta$-hCG expressing pulmonary carcinoma. (J Lung Cancer 2011;10(1):44-48)

Key Words: Pleomorphic carcinoma, Lung, Human chorionic gonadotropin

\author{
Seungeun Lee, M.D. ${ }^{1}$ \\ Ji Yun Jeong, M.D. ${ }^{1}$ \\ Joungho Han, M.D., Ph.D. ${ }^{1}$ \\ Chang Ohk Sung, M.D. ${ }^{1}$ and \\ Yong Soo Choi, M.D., Ph.D. ${ }^{2}$ \\ Departments of ${ }^{1}$ Pathology, and \\ ${ }^{2}$ Thoracic Surgery, Samsung Medical \\ Center, Sungkyunkwan University \\ School of Medicine, Seoul, Korea \\ Received: May 2, 2011 \\ Revised: June 1, 2011 \\ Accepted: June 13, 2011

\section{Address for correspondence} \\ Joungho Han, M.D., Ph.D. \\ Department of Pathology, Samsung \\ Medical Center, Sungkyunkwan Uni- \\ versity School of Medicine, 50, Irwon- \\ dong, Gangnam-gu, Seoul 135-710, \\ Korea \\ Tel: $82-2-3410-2800$ \\ Fax: 82-2-3410-0025 \\ E-mail: hanjho@skku.edu
}

\section{INTRODUCTION}

Pulmonary carcinomas are histologically composed of various subtypes, such as adenocarcinoma, squamous cell carcinoma, large cell carcinoma, and sarcomatoid carcinoma. Among them, $\beta$-human chorionic gonadotropin ( $\beta$-hCG) expression in cancer cells has been reported very rarely, only in few pulmonary carcinomas of various histological subtypes. Most histological types with $\beta$-hCG expression have been reported in adenocarcinoma, squamous cell carcinoma, or large cell pulmonary carcinoma (1-8). Untill now, $\beta$-hCG expression in pleomorphic carcinoma has been very rarely reported, only in the recent literature (9). According to a previous report,
$\beta$-hCG expression in pulmonary carcinoma seems to correlate with chemoresistance and poor prognostic factor (3). However, $\beta$-hCG expressing pulmonary carcinoma is very rare in itself, and little is known about the clinicopathological features of $\beta$ hCG expressing pulmonary carcinoma. Most of those features have been reported in a single case report, and there is no study on a large number of cases. Herein, we investigated the clinicopathologic features of six cases of $\beta$-hCG expressing pulmonary carcinoma, identified between January 1st 2006 and December 28th 2010, in a single institution. 


\section{MATERIALS AND METHODS}

\section{1) Study design and case selection}

This was a cross-sectional study of retrospective data from the surgical pathology database at the Samsung Medical Center (Seoul, Korea), between January 1st 2006 and December 28th 2010. The pathology reports were analyzed by a computer database search and cases were identified by filtering with "lung", "lobectomy", and " $\beta$-hCG" keywords, in the final pulmonary carcinoma diagnosis. Out of 2790 lobectomy specimens obtained during that period, we found six cases of $\beta$-hCG-expressing pulmonary carcinoma, and these cases were analyzed in this study. Hematoxylin and eosin (H\&E) stained slides of all six cases were reviewed by two pathologists (SEL and $\mathrm{JHH}$ ), and reclassified according to the recent WHO criteria (10). All six patients were treated uniformly by using the conventional lung cancer treatment guidelines from our institution.

\section{2) Immunohistochemical stain}

After retrieval with ER2 solution, immunohistochemical stain was performed on $3 \mu \mathrm{m}$ thick sections from each case, using the biotin-avidin-peroxidase method, on a BOND-MAX autostainer (Leica, Wetzlar, Germany). We applied the following primary antibodies: $\beta$-hCG (dilution $1: 50$, Invitrogen, USA), TTF-1 (dilution 1 : 100, DAKO, Glostrup, Denmark), and p63 (dilution $1: 1,000$, DAKO). The immunohistochemically stained slides were also independently evaluated by two pathologists (SEL and JHH).

\section{RESULTS}

The prevalence of $\beta$-hCG producing pulmonary carcinoma was $0.002 \%(6 / 2790)$ in our study period. Clinically, the patients consisted of 4 males and 2 females, ranging in age from 34 to 73 years (median, 64 years). Half of the patients presented with blood tinged sputum or hemoptysis, and all six patients had no hormonal symptoms. Three patients were smokers. The tumors were located in the right upper lobe of the lung in 4 cases, and in the right lower lobe of the lung in 2 cases. The tumor diameter ranged from 2 to $9.5 \mathrm{~cm}$, with a mean of $5.2 \mathrm{~cm}$ (median, $4.2 \mathrm{~cm}$ ). In two patients, pathological stages were IIB (T3N0M0) and IIA (T1N1M0), respectively. These patients showed very aggressive clinical course, and died within 2 months after operation, although one patient received postoperative chemotherapy. In contrast, early stage patients (stage I) lived up to 16 months during follow up period. Clinical features of patients are summarized in Table 1.

Macroscopically, all but one case showed prominent area of hemorrhage and necrosis. Representative features of our macroscopic findings are shown in Fig. 1A. Microscopically, most cases also showed prominent area of hemorrhage and necrosis, ranging from $60 \%$ to $90 \%$ (Fig. 1B). According to the recent WHO classification, all reviewed six cases were pleomorphic carcinoma, consisting of various types of nonsmall cell carcinomatous component and giant cell component. The non-small cell carcinomatous component included 4 cases of large cell carcinoma (Fig. 1C), with negative reaction for p63 immunostaining (Fig. 1C, inset), 1 case of adenocarcinoma, and 1 case of adenosquamous cell carcinoma. All cases showed various areas (range, $30 \sim 80 \%$ ) of poorly differentiated pleomorphic giant cell component, consistent with a combination

Table 1. Clinical Findings of 6 Cases of $\beta$-hCG Expressing Pulmonary Carcinoma

\begin{tabular}{|c|c|c|c|c|c|c|c|c|c|c|c|c|}
\hline Case & $\begin{array}{l}\text { Sex/ } \\
\text { Age }\end{array}$ & $\begin{array}{c}\text { Smoking } \\
(P Y)\end{array}$ & Chief complaint & Site & $\begin{array}{l}\text { Size } \\
(\mathrm{cm})\end{array}$ & pT & $\mathrm{pN}$ & Stage & ETE & Adjvant & $\begin{array}{l}\text { Follow up } \\
\text { duration (mo) }\end{array}$ & Status \\
\hline 1 & $\mathrm{M} / 73$ & 30 & Dyspnea & RUL & 4.5 & $\mathrm{~T} 2$ & NO & $\mathrm{lb}$ & - & No & 7 & NED \\
\hline 2 & $\mathrm{M} / 60$ & No & Blood tinged sputum & RUL & 9.5 & T3 & No & Ilb & - & CTX & 1 & DOD \\
\hline 3 & $\mathrm{M} / 68$ & 45 & Chest discomfort & RUL & 2 & $\mathrm{~T} 1$ & N1 & Ila & + & No & 2 & DOD \\
\hline 4 & $\mathrm{M} / 78$ & 15 & Blood tinged sputum & RUL & 5 & $\mathrm{~T} 2$ & No & $\mathrm{lb}$ & + & No & 15 & NED \\
\hline 5 & $\mathrm{~F} / 51$ & No & Hemoptysis & RLL & 4 & $\mathrm{~T} 2$ & NO & $\mathrm{lb}$ & - & CTX & 16 & AWD \\
\hline 6 & $F / 34$ & No & Abnormal Chest $\mathrm{x}$-ray & RLL & 2 & $\mathrm{~T} 1$ & No & la & - & No & 14 & NED \\
\hline
\end{tabular}

AWD: alive with disease, CTx: chemotherapy, DOD: dead of disease, ETE: endolymphatic tumor emboli, NED: no evidence of disease, PY: pack years, RLL: right lower lobe, RUL: right upper lobe. 

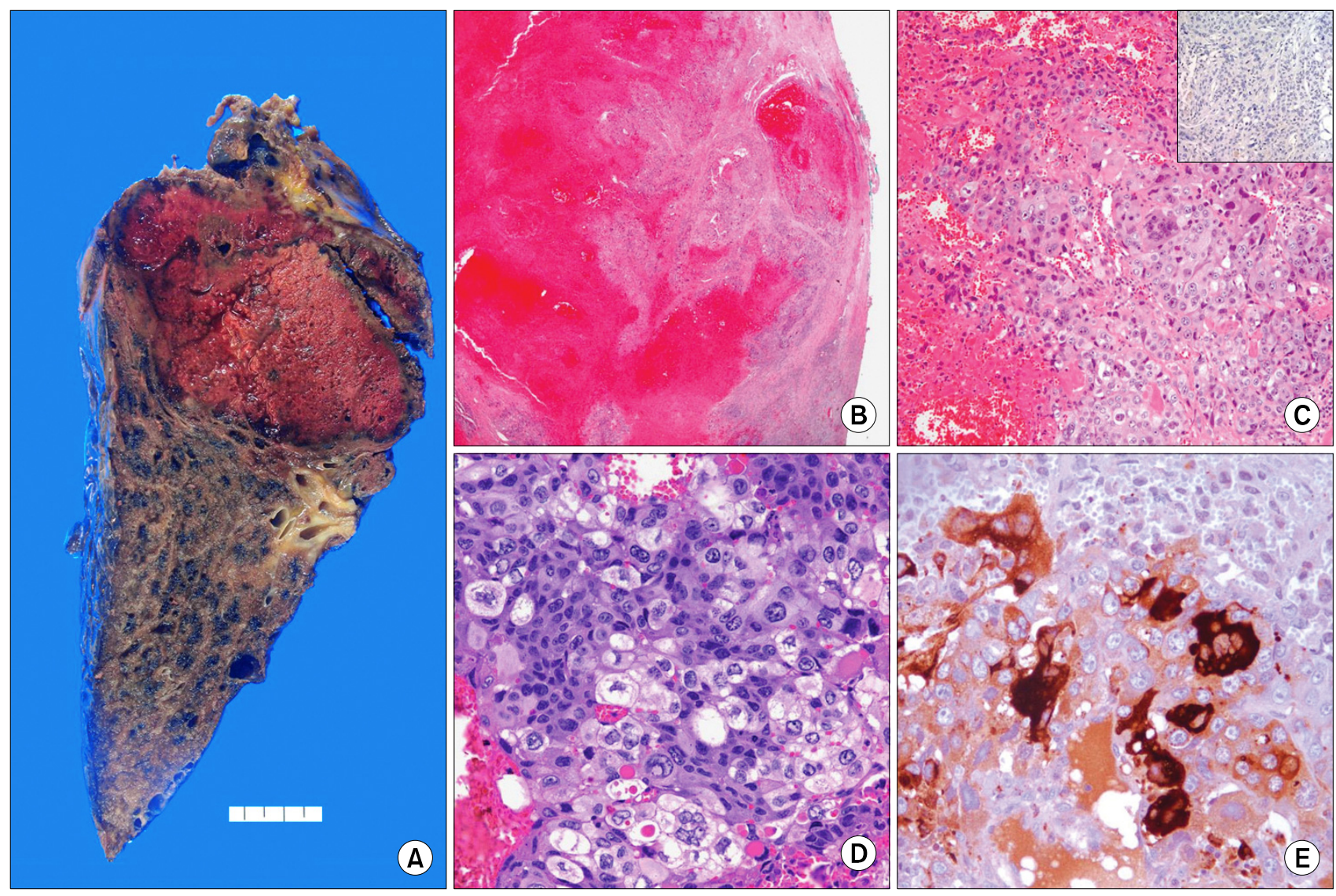

Fig. 1. Representative pathologic features of $\beta$-hCG expressing pulmonary carcinoma. (A) Gross photography shows a large necrotic mass. (B) Scanning view reveals extensive hemorrhage (hematoxylin-eosin stain, $\times 1$ ). (C) The tumor was composed of poorly differentiated large tumor cells with pleomorphic giant cells (hematoxylin-eosin stain, $\times 200$ ). The tumor cells are negative for p63 (inset) (ABC method, $\times 100)$. (D) The giant cell component shows marked pleomorphism with occasional multinucleation, which are similar morphology to syncytiotrophoblast (hematoxylin-eosin stain, $\times 400$ ). (E) Immunohistochemical stains for $\beta$-hCG shows intense cytoplasmic positive in pleomorphic giant cells (ABC method, $\times 400)$.

Table 2. Pathologic Findings in 6 Cases of $\beta$-hCG-Expressing Pulmonary Carcinoma

\begin{tabular}{|c|c|c|c|c|}
\hline \multirow{3}{*}{ Cases } & \multirow{3}{*}{ Macroscopic finding } & \multicolumn{3}{|c|}{ Microscopic finding } \\
\hline & & \multicolumn{2}{|c|}{ Viable tumor } & \multirow{2}{*}{$\begin{array}{c}\text { Hemorrhage \& necrosis } \\
\text { Amount }(\%)\end{array}$} \\
\hline & & Amount (\%) & Cell type (\%) & \\
\hline 1 & Hemorrhage and necrosis & 40 & $\begin{array}{l}\text { Large cell: } 20 \\
\text { Giant cell: } 80\end{array}$ & 60 \\
\hline 2 & Hemorrhage and necrosis & 10 & $\begin{array}{l}\text { Large cell: } 65 \\
\text { Giant cell: } 30\end{array}$ & 90 \\
\hline 3 & Solid (with necrosis) & 90 & $\begin{array}{l}\text { Adeno: } 70 \\
\text { Giant cell: } 30\end{array}$ & 5 \\
\hline 4 & Hemorrhage and necrosis & 10 & $\begin{array}{l}\text { Adenosquamous: } 20 \\
\text { Giant cell: } 80\end{array}$ & 90 \\
\hline 5 & Hemorrhage and necrosis & 20 & $\begin{array}{l}\text { Large cell: } 60 \\
\text { Giant cell: } 40\end{array}$ & 80 \\
\hline 6 & Hemorrhage and necrosis & 40 & $\begin{array}{l}\text { Large cell: } 50 \\
\text { Giant cell: } 50\end{array}$ & 60 \\
\hline
\end{tabular}


of atypical polygonal cells and multinucleated giant cells, and resembling the syntcytiotrophoblastic cells (Fig. 1D). Immnunohistochemically, non-adenocarcinomatous components were mostly negative for TTF-1. All six cases showed significant area of $\beta$-hCG positivity, and $\beta$-hCG was usually expressed in those pleomorphic giant cells (Fig. 1E). Pathologic features of the six reviewed cases are summarized in Table 2.

\section{DISCUSSION AND CONCLUSION}

Pulmonary pleomorphic carcinoma is a rare histologic type of pulmonary carcinoma; the incidence of pleomorphic carcinoma among all lung carcinomas has been reported to be $0.4 \%$, and its clinical prognosis is highly unpredictable $(11,12)$. In the rare case of pleomorphic carcinoma, pleomorphic giant cells, resembling syncytiotrophoblastic cells, are present. In this study, we report six cases of pulmonary pleomorphic carcinoma expressing $\beta$-hCG. Previously, histological types of $\beta$-hCG expressing pulmonary carcinoma have been reported in nonsmall cell carcinomas, including adenocarcinoma, squamous cell carcinoma, and large cell carcinoma. However, in this study, we identified 6 cases of $\beta$-hCG expressing pulmonary carcinoma out of 2790 lobectomy specimens, and all of the cases could be classified as pleomorphic carcinoma, according to the recent WHO classification. This discrepancy may be explained by changes of tumor classification throughout one to two decades. The fact that pleomorphic carcinoma has various components of the usual type of non-small cell carcinoma, may also cause the discrepancy. In our cases, we found large cell carcinoma in 4 cases, adenocarcinoma in 1 case, and adenosquamous cell carcinoma in 1 case. However, all of the cases had significant area of pleomorphic giant cells, which prompted the diagnosis of pleomorphic carcinoma. Identification of multinucleated giant cells, resembling syncytiotrophoblasts, and of diffuse hemorrhage and necrosis, may be helpful to differentiate the $\beta$-hCG expressing pleomorphic carcinomas from the usual pleomorphic carcinomas. Interestingly $\beta$-hCG was expressed in these pleomorphic multinucleated syncytiotrophoblastic giant cells.

A few cases presenting with hormonal symptoms, such as gynecomastia in a male patient or uterine bleeding in a female patient, associated with the pulmonary carcinoma producing $\beta$ hCG, have been reported $(6,13)$. But most of the reported patients did not show hormonal symptoms (13). Our six patients have no hormonal symptoms either. This explains why we did not measure the serum $\beta$-hCG levels in our patients. In the present cases, the $\beta$-hCG production was initially revealed by the immunohistochemical examination on surgical biopsy. Some previous reported cases of primary pulmonary choriocarcinoma may have been classified as either large cell carcinoma or pleomorphic carcinoma, and we could not deny that pleomorphic carcinoma producing $\beta$-hCG have been described as choriocarcinoma, because large cell carcinoma and pleomorphic carcinoma may occasionally include pleomorphic multi- and/or mononucleated tumor giant cells, which are similar to both syncytiotrophoblastic cells and cytotrophoblastic cells of the choriocarcinoma, and those cells are immunoreactive for $\beta$-hCG (9). Therefore, it may be difficult to clarify the differences between the primary choriocarcinoma and $\beta$ hCG-producing pulmonary carcinoma. However, in the present cases, some area of the tumors consisted of a combination of atypical polygonal cells and multinucleated giant cells, which resemble syncytiotrophoblastic cells, with no cytotrophoblastic cell, and most area showed distinctive carcinomatous components which have not been demonstrated in the case of primary pulmonary choriocarcinoma. Therefore, the present six cases were not diagnosed as primary pulmonary choriocarcinoma, but $\beta$-hCG expressing pleomorphic carcinomas of lung.

According to previous reports, $\beta$-hCG expression in pulmonary carcinoma seems correlated with both chemoresistance (3) and poor prognosis (13). In pulmonary carcinoma, the high post-operative level of serum $\beta$-hCG seemed to increase the risk of local recurrence and metastasis (9). Unfortunately, in the present cases, we could not evaluate the clinical correlation between serum $\beta$-hCG level and prognosis, because the serum $\beta$-hCG level was not routinely checked, and in a number of cases was not large. However, the present cases of stage II showed very aggressive clinical course compared to the usual pulmonary carcinomas. This suggests that $\beta$-hCG expressing pulmonary carcinoma may indeed have poor prognosis. On the other hand, the early stage (stage I) patients showed a relatively long survival rate in this study.

Many pathologists have tried to establish the concept of exemplary standard for the prognosis of these $\beta$-hCG-expressing pulmonary carcinomas. We believe it is necessary to 
pass the information about $\beta$-hCG-expressing pulmonary carcinoma on to the physicians and to inform them about the importance of checking the serum $\beta$-hCG level. We are still looking up some more reports and other studies which can support our findings.

Finally, we suggest that, in pulmonary carcinomas with multinucleated pleomorphic giant cells resembling syncytiotrophoblasts, it is necessary to check the immunohistochemical stain for $\beta$-hCG, and to follow up the serum $\beta$-hCG level to further establish the concept of $\beta$-hCG producing lung cancer.

\section{REFERENCES}

1. Fukayama M, Hayashi Y, Koike M, Hajikano H, Endo S, Okumura H. Human chorionic gonadotropin in lung and lung tumors. Immunohistochemical study on unbalanced distribution of subunits. Lab Invest 1986;55:433-443.

2. Miyake M, Ito M, Mitsuoka A, et al. Alpha-fetoprotein and human chorionic gonadotropin-producing lung cancer. Cancer 1987;59:227-232.

3. Szturmowicz M, Slodkowska J, Zych J, et al. Frequency and clinical significance of beta-subunit human chorionic gonadotropin expression in non-small cell lung cancer patients. Tumour Biol 1999;20:99-104.

4. Yokotani T, Koizumi T, Taniguchi R, et al. Expression of alpha and beta genes of human chorionic gonadotropin in lung cancer. Int J Cancer 1997;71:539-544.
5. Yoshimoto T, Higashino K, Hada T, et al. A primary lung carcinoma producing alpha-fetoprotein, carcinoembryonic antigen, and human chorionic gonadotropin. Immunohistochemical and biochemical studies. Cancer 1987;60:2744-2750.

6. Forst T, Beyer J, Cordes U, et al. Gynaecomastia in a patient with a hCG producing giant cell carcinoma of the lung. Case report. Exp Clin Endocrinol Diabetes 1995;103:28-32.

7. Ha SY, Cho HY, Lee JI. Epitheilioid trophoblastic tumor of the lung: a case report. J Lung Cancer 2009;8:114-117.

8. Okutur K, Hasbal B, Aydin K, et al. Pleomorphic carcinoma of the lung with high serum beta-human chorionic gonadotropin level and gynecomastia. J Korean Med Sci 2010;25: 1805-1808.

9. Hirano H, Yoshida T, Sakamoto $T$, et al. Pulmonary pleomorphic carcinoma producing hCG. Pathol Int 2007;57: 698-702.

10. Travis WD, Brambilla E, Muller-Hermelink HK, Harris cc (Eds). World Health Organization Classification of Tumours. Pathology and genetics of tumours of the lung, pleura, thymus and heart. IARC Press: Lyon 2004.

11. Krefting IP, Nunez LA, Sherer P, Weinstock A, Kumar A, Travis W. Pleomorphic carcinoma (spindle and giant cell) of the lung. Md Med J 1994;43:787-790.

12. Fishback NF, Travis WD, Moran CA, Guinee DG Jr, McCarthy WF, Koss MN. Pleomorphic (spindle/giant cell) carcinoma of the lung. A clinicopathologic correlation of 78 cases. Cancer 1994;73:2936-2945.

13. Ikura $\mathrm{Y}$, Inoue $\mathrm{T}$, Tsukuda $\mathrm{H}$, Yamamoto $\mathrm{T}$, Ueda $\mathrm{M}$, Kobayashi Y. Primary choriocarcinoma and human chorionic gonadotrophin-producing giant cell carcinoma of the lung: are they independent entities? Histopathology 2000;36:17-25. 